\title{
Mechanochemically Induced Anion Exchange in Aminoazobenzene Salts ${ }^{\dagger}$
}

\author{
Iva Džeba, ${ }^{a}$ Ivan Halasz, ${ }^{a}$ Kaja Lukić-Glavaš, ${ }^{b}$ and Hrvoj Vančik ${ }^{b, *}$ \\ ${ }^{a}$ Rudjer Bošković Institute, Bijenička 54, 10000 Zagreb, Croatia \\ ${ }^{\mathrm{b}}$ Department of Chemistry, Faculty of Science and Mathematics, University of Zagreb, \\ Horvatovac 102A, 10000 Zagreb, Croatia
}

RECEIVED MAY 27, 2014; REVISED AUGUST 21, 2014; ACCEPTED AUGUST 27, 2014

\begin{abstract}
Aminoazobenzene sulfate salt reacts with the crystals of $\mathrm{KBr}$ in solid-state under high pressure yielding corresponding bromide salt. The reactant and product differ also in the position of protonation, amino group, and azo group, respectively. Since protonation of azo-group destroys the coplanarity of two benzene rings and diminishes $\pi$-conjugation, the product differs from the reactant also in color, from orange to violet. Hence, the reaction is the example of the piezochromic effect. This solid-state process is studied by kinetic measurements, and the structures of the compounds were analyzed by X-ray chrystallography.
\end{abstract}

Keywords: mechanochemistry, solid-state reaction, azobenzene, Avrami equation, piezochromism

\section{INTRODUCTION}

Solid-state chemistry is a fast-developing science, enhanced by its numerous applications in the high technology industries. Often depending on specific crystal modification and high temperature interaction, it is associated with both, inorganic and organic crystalline compounds, where reactions are thought to occur via ion displacement and crystal deformation mechanisms. ${ }^{1}$

Mechanically induced solid-state reactions are attracting the interest of scientists, especially those engaged in the quest for solvent free chemical processes, development of new methods for the synthesis of pharmaceuticals, molecular electronic devices, as well as designing of new materials with special properites. ${ }^{1}$ Although the observation and the study of the mechanically induced chemical processes has been introduced more than hundred years ago, ${ }^{2}$ the intensive and systematic development of this field of chemistry became actual in last decade. ${ }^{3}$ In addition to the synthetic applications of such reactions, it is also of fundamental interest to establish the mechanistic basis of these processes in the frame of mechanistic concepts developed in our previous studies in the field of solid-state reactions in the molecular crystals. ${ }^{4}$ It is still an open question about the details of the mechanisms of these processes. ${ }^{5}$ For instance, it is not clear whether the reaction really occurs between solids, or whether the formation of a microliquid phase between reactants is fundamental for the reactivity. ${ }^{6} \mathrm{In}$ this work we present our structural and kinetic investiga- tions of the effect of high pressure on solid-state reactions of anion exchange in aminoazobenzene salts.

Alkaline metal halides, used as pelleting matrices for IR-spectroscopy are known in some cases to interact physically or chemically with the embedded samples. ${ }^{7}$ In most cases an ion exchange between pelleting and sample materials occurs. Some of these interactions were confirmed by spectroscopy and x-ray crystallography. ${ }^{8}$ Molecular rearrangements induced by high pressure can afford conformational transformations, and/or proton transfer, what can occasionally be observed as a change in color (piezochromism).

The high pressure induced reaction between solid salts of 4-aminoazobenzene (1) (Scheme 1) and solid potassium bromide was selected as a molecular model

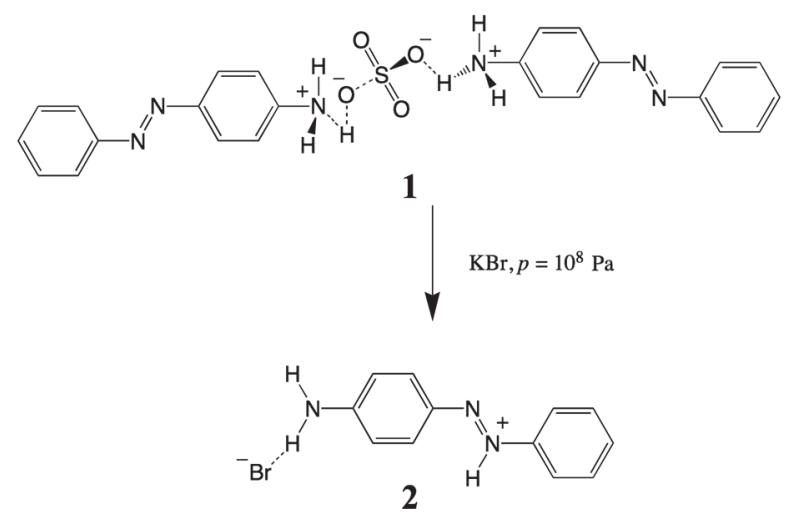

Scheme 1.

\footnotetext{
$\dagger$ Dedicated to Dr. Mirjana Eckert-Maksić on the occasion of her $70^{\text {th }}$ birthday.

* Author to whom correspondence should be addressed. (E-mail: vancik@chem.pmf.hr)
} 

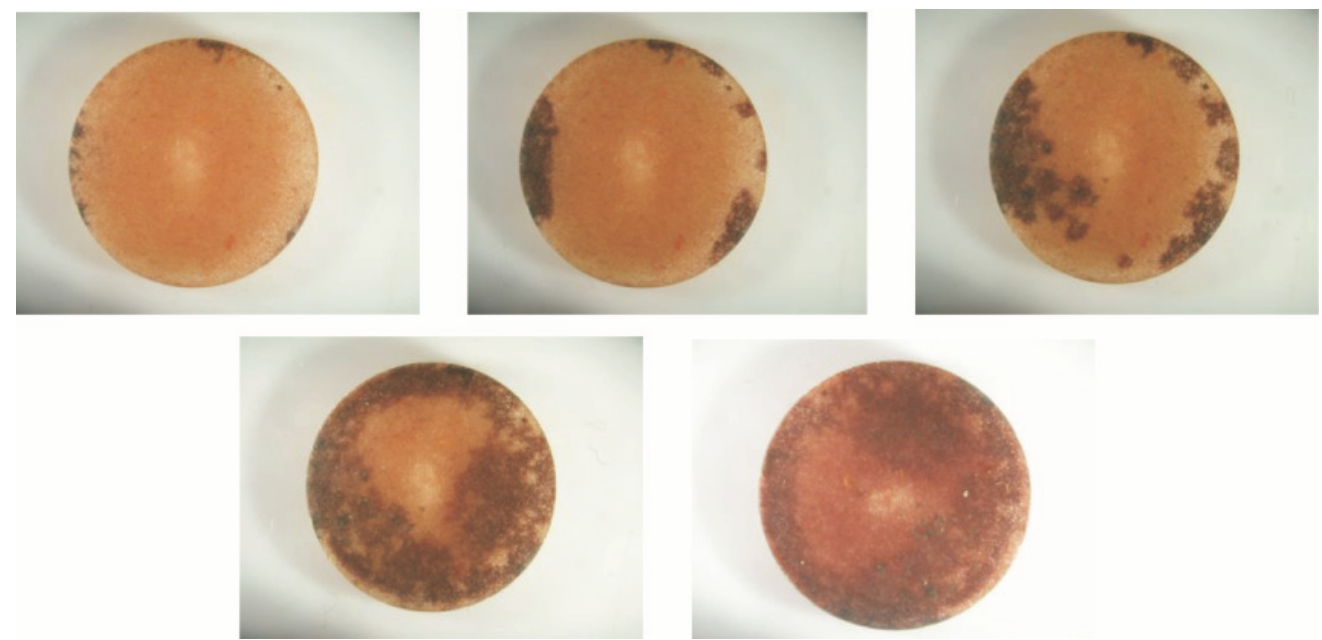

Figure 1. Photograph of sulfate salt $\mathbf{1}$ in $\mathrm{KBr}$ pellet at different time after application of $10 \mathrm{kbar}$ pressure.

for extending our investigation of solid-state reaction mechanisms.

\section{RESULTS AND DISCUSSION}

Reaction of the Sulfate Salt of 4-aminoazobenzene (1) in KBr Pellet

In typical experiment, crystals of 1 were ground with dry alkali metal halide powder $(1-2 \%)$ and pressed to $\approx$ 10 kbar. After 3-5 minutes of pressing, the pellet started to change its color (Figure 1). Expecting that the mechanically induced chemical transformation includes anion exchange (sulfate with bromide), we have extra prepared the bromide salt 2 , and we found that its spectrum agrees almost perfectly with the spectrum of the product. The reaction includes both, anion exchange and the protonation of the nitrogen atom of the azo group (Scheme 1).

The rate of the color change depended on the mode of the pellet preparation (mixing of the compound with $\mathrm{KBr}$ ), and on the initial pressure. In most cases it was possible to visualize the reaction flow (Figure 1). The reaction rate also depends on the size of crystals of potassium bromide. If we use standard $\mathrm{KBr}$ salt without further sieving, then the reaction is much faster than that with reduced particle size of $\mathrm{KBr}$. Since the reaction could be sensitive to moisture, the experiments were followed under dry conditions. In that case no reaction was observed without the mechanical force. We also have tested the efficiency of the reaction by using different pressures. The data in Table 1 show that the reaction rate strongly increases if a higher mechanical force is applied.

On the basis of the available literature data ${ }^{9}$ (Table 2 ), we suppose that the color change of 4-aminoa-

Table 1. Effect of the initial pressure on the reaction degree $\alpha$

\begin{tabular}{cc}
\hline $\begin{array}{c}\text { Initial pressure } \\
\left(\mathrm{kbar} / \mathrm{cm}^{2}\right)\end{array}$ & $\alpha($ for $t=30 \mathrm{~min})$ \\
\hline 4 & 0 \\
6 & 0.09 \\
8 & 0.37 \\
10 & 0.55 \\
\hline
\end{tabular}

Table 2. Color of differently protonated 4-aminoazobenzene salts

\begin{tabular}{lll}
\hline 4-aminoazobenzene salt & Color & Protonated nitrogen \\
\hline sulphate & orange & amino group \\
hidrogensulphate & violet & azo group \\
hidrogenphosphate & orange & amino skupina \\
dihidrogenphosphate & violet & azo group \\
bromide & violet & azo group \\
iodide & greenish & azo group \\
Oxalate* & orange & amino group \\
chloride* & violet & azo group \\
phenylphosphonate* & orange & amino group \\
$1,4-b u t a n d i p h o s p h o n a t e *$ & orange & amino group \\
\hline
\end{tabular}

*Ref. 9 . 


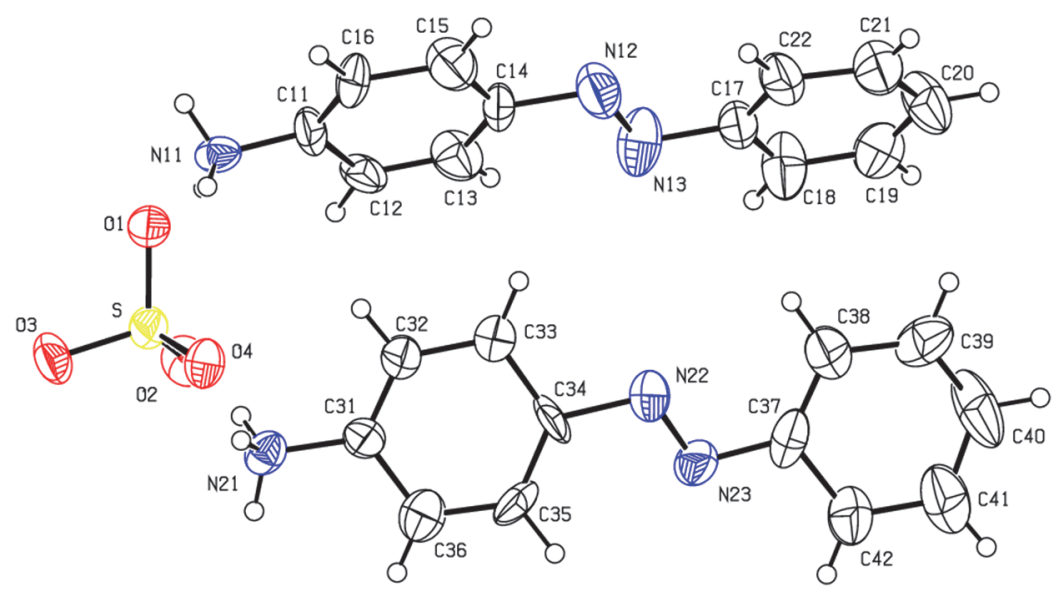

Figure 2. ORTEP III represented molecular structure of $\mathbf{1}$.

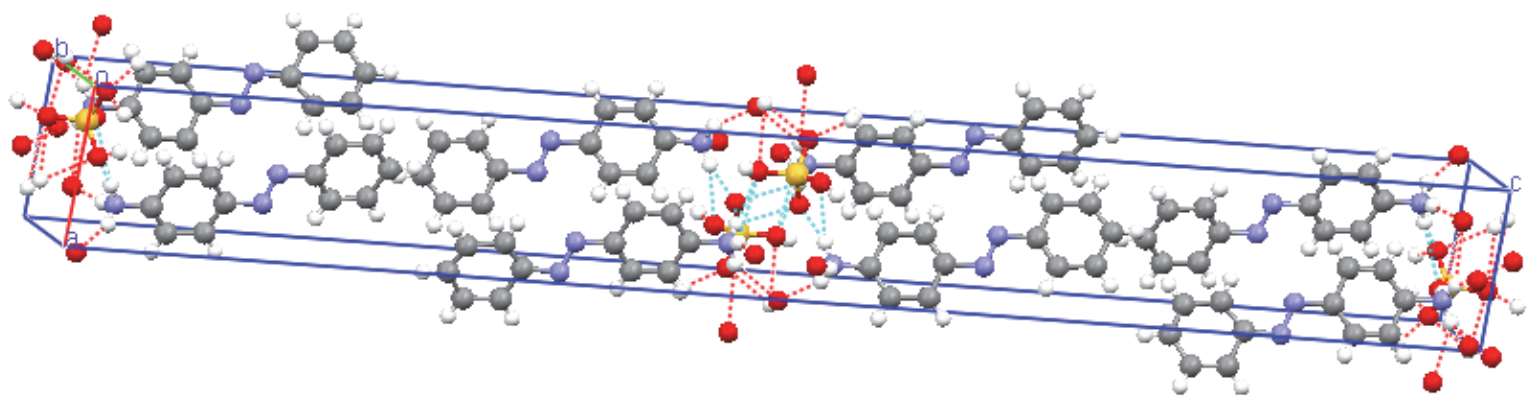

Figure 3. Crystal packing of $\mathbf{1}$ with the protonated amino groups.

zobenzene salts depends on the protonation of particular nitrogen-atom. While the protonation of amino nitrogen atom causes orange color, the protonation of azo-group nitrogen paints the salt in violet.

\section{Molecular and Crystal Structures}

The sulfate and bromide salts (1 and 2) were analyzed by X-ray christalography. Their molecular and crystal structures are shown in the Figures 2-5.

Molecular structures of the orange sulfate 1 and the violet bromide $\mathbf{2}$ obtained from X-ray crystalog-

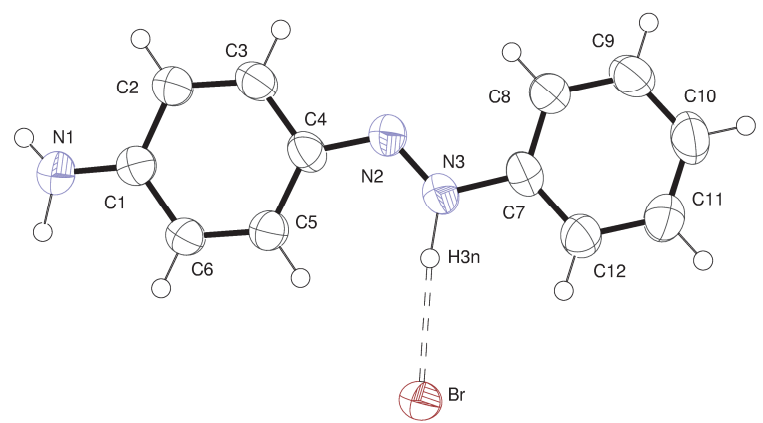

Figure 4. Figure 2 ORTEP III represented molecular structure of 2. raphy differs in the coplanarity of the benzene rings. In the azo-protonated molecule $\mathbf{2}$ the twisting angle between phenyl rings is $7.4^{\circ}$ what is substantially larger than in amino group protonated molecule $\left(3.16^{\circ}\right)$. Such larger twisting diminishes $\pi$-electron conjugation in the bromide salt causing the blue shift in the UV-VIS spectrum of 2. Similar structural effect on the change in

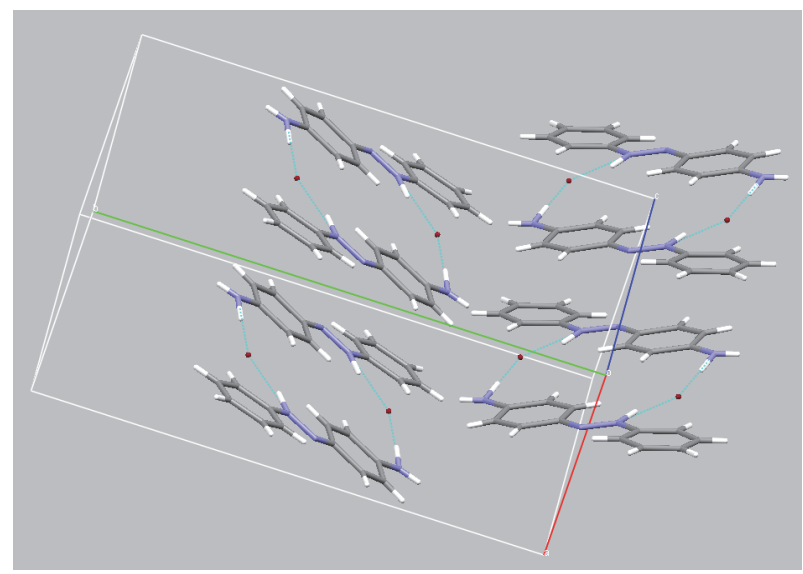

Figure 5. Crystal packing of $\mathbf{2}$ with the protonated azo groups and the hydrogen bond network. 


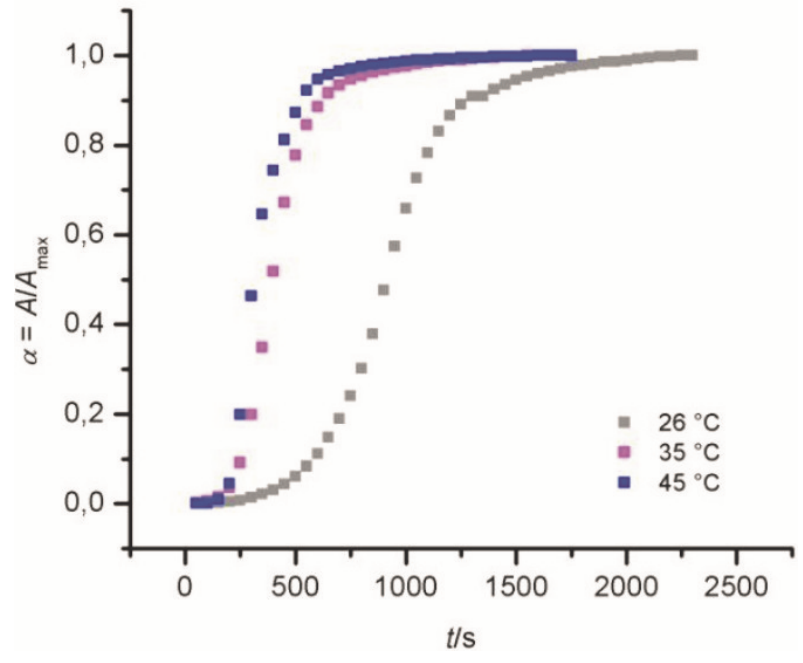

Figure 6. Kinetic curves for the reaction of $\mathbf{1}$ in the $\mathrm{KBr}$ pellet measured at different temperatures. Degree of the reaction $(\alpha)$ is plotted versus time for following the intensity of the $\mathrm{C}-\mathrm{N}$ stretching signal at $1278 \mathrm{~cm}^{-1}$.

color has been previously observed for the hydrogen and dihydrogen phosphate salts of 4-aminoazobenzene salts. ${ }^{9 b}$

\section{Kinetic Measurements}

The rates of the reactions were measured by following the sharp IR signal at $1278 \mathrm{~cm}^{-1}$ assigned to $\mathrm{C}-\mathrm{N}$ stretching. The obtained kinetic curves are sigmoids, typical for the most of the previously studied solid-state reactions (Figure 6). The reaction is temperature dependent, so that the $t_{1 / 2}$ (the inflexion point) is reached after $900 \mathrm{~s}\left(26^{\circ} \mathrm{C}\right), 400 \mathrm{~s}\left(35^{\circ} \mathrm{C}\right)$, and $300 \mathrm{~s}\left(45^{\circ} \mathrm{C}\right)$.

The best curve fitting for all the measurements is with the Avrami-Erofeev mathematical model for analysis of solid-state transformatios. ${ }^{10}$ The model that is in literature also known as the Johnson-Mehl-AvramiKolmogorov approach (JMAK) is based on the concept that the solid-state reaction begins with nucleation of new product crystal phase within the bulk of the reactant phase. Starting from these nuclei the product phase continue to growth following the exponential kinetics:

$$
\alpha=1-\exp \left(-r t^{n}\right)
$$

where $\alpha$ is the degree of the reaction, $r$ is reaction rate, $t$ is reaction time, and $n$ depends on the dimensionality of the development of the product phase and the type of the process. In all the measurements the maximal $n$ value falls between 3.00 and 3.5 indicating the threedimensional growth of the product phase.

By exposing the mixture of $\mathrm{KBr}$ with $\mathbf{1}$ to the atmosphere saturated with moisture (99\%) without using the mechanical pressure the same bromo-salt has been isolated. Evidently, the reaction can follow two mecha- nisms, in moisture doped solid-state mixture or mechanochemically. The exact role of the moisture remains still an open question.

\section{CONCLUSIONS}

The sulfate salt of aminoazobenzene (1) reacts in the solid-state with $\mathrm{KBr}$ under the high mechanical pressure by formation of the bromide salt (2). The reactant and the product differ in the position of protonation: amino group in $\mathbf{1}$, and azo-group in $\mathbf{2}$. The reaction is piezochromic because the reactant and the product markedly differ in color. From the molecular structures of the reactant $\mathbf{1}$ and the product $\mathbf{2}$ obtained by X-ray crystallography it follows that the change in color (blue-shift) is a consequence of the reduced $\pi$-conjugation in $\mathbf{2}$ caused by the increase in the twisting angle between two benzene rings (from $3.16^{\circ}$ in 1 to $7.4^{\circ}$ in $\mathbf{2}$ ).

Kinetics of the process affords typical sigmoid curve that could be represented by the Avrami-Erofeev nucleation and growth model with the three-dimensional development of the product phase. Findings described in this work open the question about the mechanism of this reaction from the physical-organic chemistry point of view. The study that includes the detailed quantum chemical calculations and molecular dynamics is in progress in our research group.

\section{EXPERIMENTAL}

NMR spectra were taken on the Bruker AV 600 at 600 $\left({ }^{1} \mathrm{H}\right)$ i $75\left({ }^{13} \mathrm{C}\right) \mathrm{MHz}$ in $\mathrm{CDCl}_{3}$ and DMSO with TMS as an internal standard.

IR spectra were recorded in the $4000-400 \mathrm{~cm}^{-1}$ region on EQUINOX 55 FT-IR spectrometer (Bruker Optic GmBH).

Preparation of Compounds

Sulphate salt of 4-aminoazobenzene (1): $0.2 \mathrm{~g}$ (1 mmol) of 4-aminoazobenzene (Aldrich chemicals) was dissolved in a mixture of $4 \mathrm{ml}$ glacial acetic acid, $0.2 \mathrm{ml}(7 \mathrm{mmol})$ $30 \%$ hydrogen peroxide, and $0.1 \mathrm{ml}$ conc. sulfuric acid. After the mixture was allowed to stand 5 minutes at room temperature, the crude residue was filtered off, recrystalized from $20 \mathrm{ml}$ ethanol, and then dried in exicator. The resulting orange crystalline product melts with decomposition above $210^{\circ} \mathrm{C}$. (Yield: $0.2 \mathrm{~g} ; 68 \%$ ).

Bromide salt of 4-aminoazobenzene (2): A solution of $0.4 \mathrm{~g}(2 \mathrm{mmol})$ of 4-aminoazobenzene in ethanol was added to aqueous solution of potassium bromide $(0.24 \mathrm{~g}$ $\mathrm{KBr}$ in $5 \mathrm{ml}$ water). The mixture was allowed to stand at room temperature for 25 hours. The resulting violet crystals were filtered off, washed with diethyl-ether, and dried in air. The product melted with decomposition above $198{ }^{\circ} \mathrm{C}$. (Yield: $0.62 \mathrm{~g} ; 91 \%$ ) 


\section{X-ray Crystallography Data}

Crystal Data

Formula

Relative molecular mass

Crystal system and space group

Unit cell parameters:

Number of formula units, $Z$

Calculated density, $D_{x}$

Source, $\lambda$, Mo K $\alpha$

Difractometer

Data collection

Temperature, $T$

Linear absorption coeffitient

Crystal color and shape

No of measured reflexes

No of independent reflexes

No of observed reflexes

Criterium for observed reflexes

Validity of equivalent reflexes, $R_{\text {int. }}$

$\theta_{\text {maks }}$

No of optimizing parameters

$R, w R\left[F_{\mathrm{o}}{ }^{2} \geq 2 \sigma\left(F_{\mathrm{o}}{ }^{2}\right)\right]$

$0.2091, \quad 0.5593$

$R, w R$ (all data)

$0.2245, \quad 0.5785$

$S$

Weight scheme:

$w=1 /\left[\sigma^{2}\left(F_{\mathrm{o}}{ }^{2}\right)+(0.1021 P)^{2}+1.0658 P\right]$

$(\Delta / \sigma)_{\max }$

$(\Delta / \sigma)_{\text {mean }}$

$\Delta \sigma_{\text {max. }}, \Delta \sigma_{\text {min. }}$

$1.323-1.298$ e $\AA^{3}$

Formula

Relative molecular mass

Crystal system and space group

Unit cell parameters:

\section{$\mathrm{C}_{12} \mathrm{H}_{12} \mathrm{Br} \mathrm{N}$}

$278.15 \mathrm{~g} / \mathrm{mol}$

Monoclinic, $P 2_{1} / c$

$a=7.3129$ (17) $\AA$ $b=18.945$ (3) $\AA$

$c=9.1220(15) \AA$

$\alpha=90.00$

$\beta=111.75$ (2) ${ }^{\circ}$

$\gamma=90.00^{\circ}$

$V=1173.82 \AA^{3}$

Number of formula units, $Z$

Calculated density, $D_{x}$

$1.568 \mathrm{mg} \mathrm{m}^{-3}$

Source, $\lambda$, Mo K $\alpha$

$0.71073 \AA$

Difractometer

Oxford Xcalibur 3

Data collection

Temperature, $T$

293(2) K

Linear absorption coeffitient

$3.447 \mathrm{~mm}^{-1}$

Crystal color and shape

Violet prism

No of measured reflexes

5877

No of independent reflexes

3040

No of observed reflexes

1340

Criterium for observed reflexes

$[I \geq 2 \sigma(I)]$

Validity of equivalent reflexes, $R_{\text {int. }}$

$\theta_{\text {maks }}$

$30.50^{\circ}$

No of optimizing parameters

148

$R, w R\left[F_{\mathrm{o}}{ }^{2} \geq 2 \sigma\left(F_{\mathrm{o}}{ }^{2}\right)\right]$

$0.052, \quad 0.1371$

$R, w R$ (all data)

$0.1354,0.1929$

$S$

0.911

Weight scheme:

$w=1 /\left[\sigma^{2}\left(F_{\mathrm{o}}{ }^{2}\right)+(0.1021 P)^{2}+1.0658 P+0.0000 P\right]$

$$
\begin{array}{lr}
(\Delta / \sigma)_{\text {max. }} & 0.001 \\
(\Delta / \sigma)_{\text {mean }} & <0.001 \\
\Delta \sigma_{\text {max. }}, \Delta \sigma_{\text {min. }} & 0.602-0.736 \text { e } \AA
\end{array}
$$

Acknowledgements. This work was supported by the Department of Chemistry, Faculty of Science, University of Zagreb.

\section{REFERENCES}

1. (a) K. S. Suslick, Faraday Discuss. (2014) DOI: 10.1039/C4FD00148F; (b) D. Braga and F. Grepioni, Acc. Chem. Res. 33 (2000) 6001; (c) V. P. Balema, J. W. Wiench, M. Pruski, and V. K. Pecharsky, J. Am. Chem. Soc. 124 (2002) 6244; (d) P.N. Chen, C.-C. Lai, and S.-H. Chiu, Org. Lett. 13 (2011) 4660; (e) D. Cinčić, I. Brekalo, and B. Kaitner, Cryst. Growth Des. 12 (2012) 44; (f) B. Rodriguez, A. Bruckmann, T. Rantanen, and C. Bolm, Adv. Synth. Catal. 349 (2007) 2213; (g) Y.-F. Wang, R.X. Chen, K. Wang, B.-B. Zhang, Z.-B. Li, and D.-Q. Xu, Green Chem. 14 (2012) 893.

2. (a) P. G. Fox, J. Mat. Sci. 10 (1975) 340; (b) L. Takacs, Chem. 
Soc. Rev. 42 (2013) 7649-7659.

3. (a) S. L. James and T. Friščić, Chem. Soc. Rev. 42 (2013) 7494; (b) D. Braga, L. Maini, and F. Grepioni, Chem. Soc. Rev. 42 (2013) 7638; (c) G.-W. Wang, Chem. Soc. Rev. 42 (2013) 7668; (d) S.-E. Zhu and G.-W. Wang, Chem. Soc. Rev. 42 (2013) 7535.

4. (a) I. Halasz and H. Vančik, CrystEngComm 13 (2011) 4307; (b) I. Halasz, E. Meštrović, H. Čičak, Z. Mihalić, and H.Vančik, J. Org. Chem. 70 (2005) 8461. (c) H. Vančik, V. ŠimunićMežnarić, E. Meštrović, and I. Halasz, J. Org. Chem. 69 (2004) 4829. (d) A. Maganjić, I. Šolić, S. Milovac, I. Halasz, I. Biljan, and H. Vančik, J. Phys. Org. Chem. 27 (2014) 177.

5. E. Boldyreva, Chem. Soc. Rev. 42 (2013) 7719.
6. G. Rothenberg, A. P. Downie, C. L. Raston, and J. L. Scott, J. Am. Chem. Soc. 123 (2001) 8701.

7. D. Braga, L. Maini, M. Polito, and F. Grepioni, Chem. Commun (2002) 2302

8. D. Braga, L. Maini, and F. Grepioni, Chem. Commun. (1999) 937.

9. (a) F. H. Allen, Acta Cryst. B 58 (2002) 380; (b) I. Halasz, K. Lukić, and H. Vančik, Acta Cryst. C 63 (2007) 061

10. (a) M. Avrami, J. Chem. Phys. 7 (1939) 1103; (b) M. Avrami, J. Chem. Phys. 8 (1940) 212; (c) M. Avrami, J. Chem. Phys. 9 (1941) 177; (d) B. V. Erofeev, Compt. Rend. Acad. Sci. USSR 52 (1946) 511 


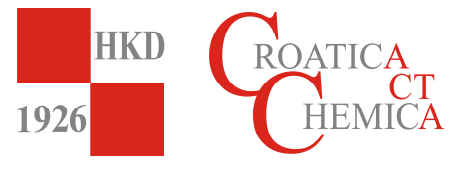

\section{Corrigendum}

Croat. Chem. Acta 87 (2014) 407-412

"Mechanochemically Induced Anion Exchange in Aminoazobenzene Salts"

Iva Džeba, Ivan Halasz, Kaja Lukić-Glavaš, and Hrvoj Vančik

The affiliation of all authors should be:

"Department of Chemistry, Faculty of Science, University of Zagreb, Horvatovac 102a, 10000 Zagreb, Croatia". 